
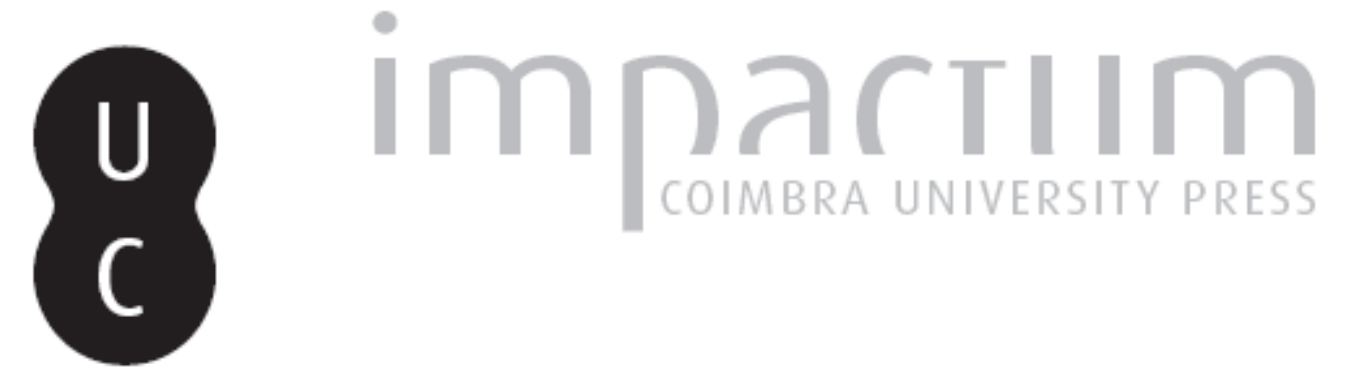

\title{
[Recensão a] Anthony Francis Natoli: The Letter of Speusippus to Philip II. Introduction, Text, Translation and Commentary
}

Autor(es): Schorn, Stefan

Publicado por: Imprensa da Universidade de Coimbra

URL persistente:

URI:http://hdl.handle.net/10316.2/42220

DOI:

DOl:https://doi.org/10.14195/2183-4105_7_5

Accessed : $\quad$ 26-Apr-2023 14:22:44

A navegação consulta e descarregamento dos títulos inseridos nas Bibliotecas Digitais UC Digitalis, UC Pombalina e UC Impactum, pressupõem a aceitação plena e sem reservas dos Termos e Condições de Uso destas Bibliotecas Digitais, disponíveis em https://digitalis.uc.pt/pt-pt/termos.

Conforme exposto nos referidos Termos e Condições de Uso, o descarregamento de títulos de acesso restrito requer uma licença válida de autorização devendo o utilizador aceder ao(s) documento(s) a partir de um endereço de IP da instituição detentora da supramencionada licença.

Ao utilizador é apenas permitido o descarregamento para uso pessoal, pelo que o emprego do(s) título(s) descarregado(s) para outro fim, designadamente comercial, carece de autorização do respetivo autor ou editor da obra.

Na medida em que todas as obras da UC Digitalis se encontram protegidas pelo Código do Direito de Autor e Direitos Conexos e demais legislação aplicável, toda a cópia, parcial ou total, deste documento, nos casos em que é legalmente admitida, deverá conter ou fazer-se acompanhar por este aviso.

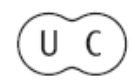




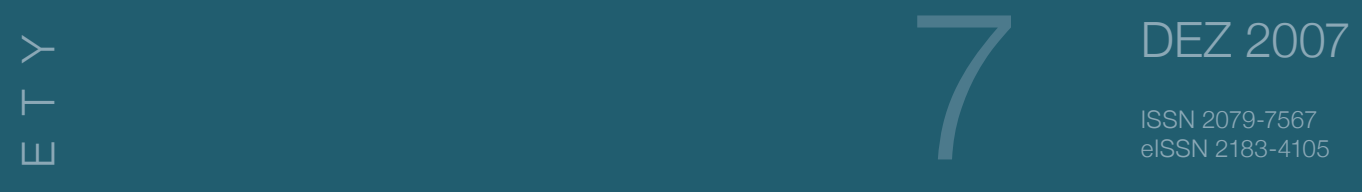

$-$

0

○

$\infty$

Established 1989

http://platosociety.org/

O

$\vdash$

$\varangle$

\lrcorner

口

-
$\varangle$
$Z$
0
-
-
$\varangle$
$Z$
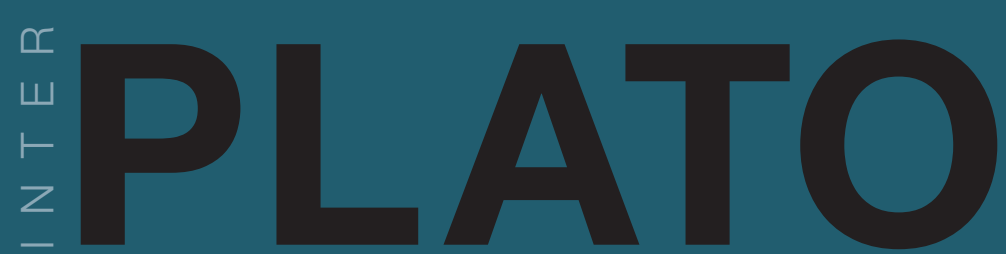

J0
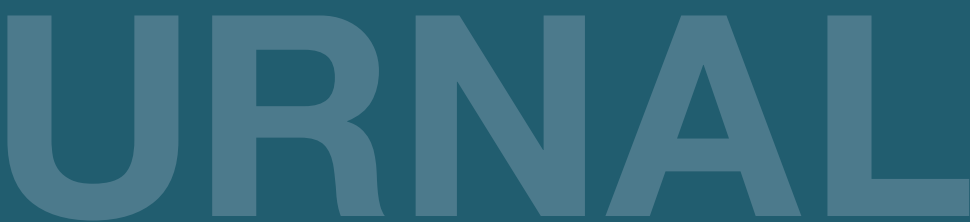

Société Platonicienne Internationale

Associazione Internazionale dei Platonisti

Sociedad Internacional

de Platonistas

Internationale

Platon-Gesellschaft 


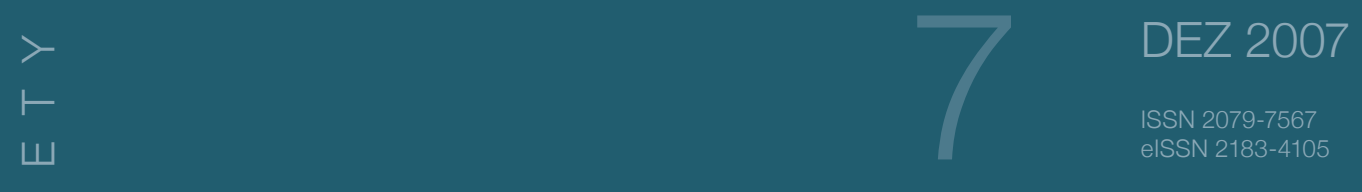

$-$

0

○

$\infty$

Established 1989

http://platosociety.org/

O

$\vdash$

$\varangle$

\lrcorner

口

-
$\varangle$
$Z$
0
-
-
$\varangle$
$Z$
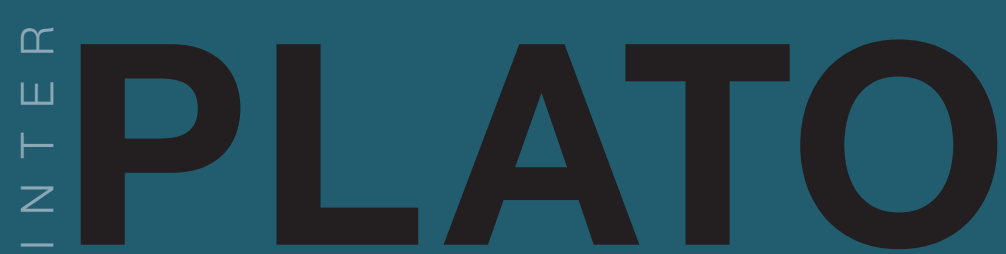

J0
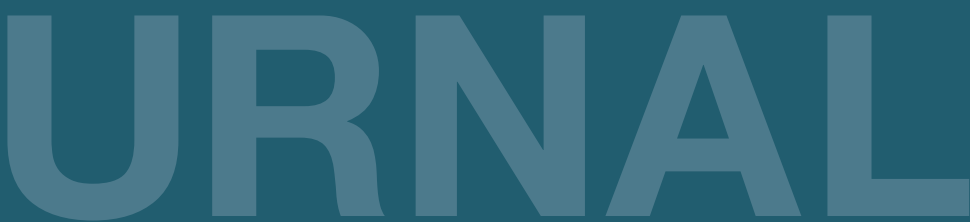

Société Platonicienne Internationale

Associazione Internazionale dei Platonisti

Sociedad Internacional

de Platonistas

Internationale

Platon-Gesellschaft 
Anthony Francis Natoli: The Letter of Speusippus to Philip II. Introduction, Text, Translation and Commentary. Stuttgart (Steiner) 2004. Historia, Einzelschriften: 176."

Seitdem E. Bickermann und J. Sykutris (B.-S.) im Jahr 1928 nach einer detaillierten inhaltlichen und sprachlichen Analyse zu dem Ergebnis gekommen sind, daß es sich beim 30. Sokratikerbrief um ein genuines Schriftstück des Speusippos an König Philippos von Makedonien handle, galt die Autorschaft meist als entschieden. ${ }^{1}$ Auch Natoli (N.), der diesen Text nun wieder neu herausgegeben, kommentiert und eingehend interpretiert hat, schließt sich dieser Zuweisung an.

Der Brief gibt sich als ein Empfehlungsschreiben für einen sonst nicht bekannten Antipatros aus Magnesia, der seit einigen Jahren in Athen lebt und dort an einer Geschichte Griechenlands schreibt. Dieser ist der Überbringer des Briefes und möchte vom König Unterstützung hinsichtlich eines Unrechts erhalten, das ihm in seiner Heimatstadt widerfahren ist ( $§ 1)$. Speusippos stellt Antipatros als einen Mann dar, der für Philippos im Propagandakrieg in Griechenland von großem Nutzen sein könne. Um dies zu verdeutlichen, legt er detailliert die Kritik dar, die Antipatros in der Akademie bei einer Diskussion über den ,Philippos' des Isokrates an dieser Schrift geübt habe. Isokrates habe es versäumt, die Wohltaten des Philippos und seiner Vorfahren zu erörtern, was Speusippos (nach Antipatros) im folgenden nachholt (§ 2-4). Im Anschluß legt Speusippos dar, wie Antipatros in seinem Geschichtswerk durch mythische Konstrukte um Herakles, den Ahnherrn des makedonischen Königshauses, den Anspruch Makedoniens auf die zwischen ihm und Athen strittigen Städte Amphipolis und Chalkidike sowie auf Ambrakia untermauert habe (§ 5-7). Durch entsprechende ,Präzedenzfälle' legitimiert Antipatros dort ebenso die Übernahme der beiden Stimmen der Phoker in der delphischen Amphiktyonie durch Philippos (§ 8-9). Der Brief endet mit einer heftigen Polemik gegen Isokrates und seine Schüler Isokrates von Apollonia und Theopompos (letzterer hält sich gerade am makedonischen Hof auf), die diesen die Kompetenz als Schriftsteller und politische Berater abspricht (§ 9$14)$.

In einer umfangreichen Einleitung faßt N. die Ergebnisse seines ausführlichen und sorgfältigen Zeilenkommentars zusammen und bietet eine Gesamtinterpretation des Briefes. N. argumentiert gegen die Auffassung von B.-S., der Brief sei von Speusippos zur Veröffentlichung bestimmt gewesen und sieht in ihm einen Privatbrief (2022). In seiner Argumentation für die Echtheit folgt er weitgehend B.-S., mit kleinen Änderungen jedoch, die durch seine Einschätzung des Schriftstücks als Privatbrief bedingt sind, und kommt auf eine Datierung von 343-341, wobei ihm 342 als am wahrscheinlichsten erscheint (23-31). Er erweitert somit die sehr enge Datierung von B.-S., die den Brief in den Winter 343/2 gesetzt hatten.

Im Herzstück der Einleitung verortet Natoli den Brief im Kontext des 4. Jh.s. (32-66). In detaillierten Analysen untersucht er die Beziehungen zwischen Philippos

\footnotetext{
* Diese Besprechung wurde zuerst in Gymnasium 113, 2006, 472-474, veröffentlicht. Ich danke dem Universitätsverlag Winter für die Erlaubnis, sie an dieser Stelle erneut zu publizieren.

${ }^{1}$ E. Bickermann und J. Sykutris, Speusipps Brief an König Philipp. Text, Übersetzung, Untersuchungen (BSG 80,3), Leipzig 1928. Der Brief trägt keinen Absender, doch referiert aus ihm der Historiker Karystios (FHG IV $356=$ Athen. 11,506e-f) und nennt als Autor Speusippos.
} 
II. (und seinen Vorgängern) und den Intellektuellen in Athen: Platon, Euphraios von Oreos, Speusippos, Xenokrates, Aristoteles, Isokrates, Theopompos von Chios, Anaximenes von Lampsakos und Kallisthenes von Olynth. Er begibt sich hierbei auf ein bekanntermaßen schwieriges Terrain. Denn es gibt hierfür zwar eine Reihe zeitgenössischer Quellen und Angaben späterer Historiker, doch ist deren Echtheit bzw. Glaubwürdigkeit Gegenstand lebhafter Kontroversen. Im Falle des Isokrates und seiner Schüler ist die Echtheit der in diesem Kontext relevanten Isokratesbriefe durch Referenzen in anderen Schriften des Publizisten in glücklicher Weise erwiesen. N.s sorgfältige Rekonstruktion der Geschichte der Beziehung zwischen Isokrates und dem Makedonen steht daher auf einem soliden Fundament. Schwieriger ist die Situation im Hinblick auf das Verhältnis zwischen Platon und Philippos. N. sucht nachzuweisen, daß Philippos aufgrund von Ereignissen, die sich zur Zeit der Regierung seines Bruders Perdikkas zugetragen haben und auf die der 5. platonische Brief Bezug nimmt, Platon gegenüber feindlich gesinnt gewesen sei. Mehr als 20 Jahre später habe Speusippos durch seinen Brief versucht, den Kontakt wiederherzustellen und Patronage des makedonischen Königs zu gewinnen, doch habe dieser Versuch keinen Erfolg gebracht $(27$; 64-66; 94-100). Diese Rekonstruktion scheint mir problematisch zu sein. N. geht von der Echtheit des 5. platonischen Briefes aus bzw. davon, daß dieser authentisches Material überliefert. Ebenso schenkt er weithin der Überlieferung des Theopompos und des Historikers Karystios (2. Jh. v.Chr.) über die Beziehung zwischen Platon und Philippos Glauben, die allerdings einer dezidiert platonfeindlichen Richtung angehören. Es wäre nötig, vom wenigen Sicheren ausgehend, nach dem Verhältnis zwischen Platon und Philippos zu fragen, und dann die unsicheren Zeugnisse mit einzubeziehen und zu prüfen, ob sie echt sein können bzw. wann jemand ein Interesse gehabt haben kann, diese Dokumente zu fälschen

Gegen die Interpretation von Speusippos' Brief als Versuch, nach Jahren der Gegnerschaft und der fehlenden Kommunikation wieder ein freundschaftliches Verhältnis zum makedonischen Königshof herzustellen, spricht, daß der Brief ohne Höflichkeitsfloskeln sogleich mit der Forderung nach Hilfe für Antipatros beginnt (§ 1) und im Ton so gehalten ist, als sei Speusippos in einer Position, in der er diese Unterstützung erwarten könne. Mit anderen Worten: der Brief setzt ein gutes Verhältnis zwischen der Akademie und Philippos voraus. Die scharfe Polemik gegen Isokrates und seine Schüler, die alle in hohem Ansehen bei Philippos gestanden zu haben scheinen, wäre zudem kontraproduktiv gewesen, wollte man nach einer Phase der Entfremdung wieder ein normales oder freundschaftliches Verhältnis zum Makedonenkönig herstellen.

Von großem Interesse sind N.s überzeugende Analysen der (pseudo)historischen Angaben in dem Brief über die Vorfahren des Makedonenkönigs und über die angeblichen Präzedenzfälle für den Ausschluß der Phoker aus der delphischen Amphiktyonie sowie seine Interpretation der Kritik des Speusippos am ,Philippos' des Isokrates. N. erklärt die mythologischen Konstrukte unter Heranziehung von Parallelmaterial, illustriert die Relevanz solcher Erzählungen in der Politik des 4. Jh.s und arbeitet die Tendenzen der unterschiedlichen Berichte heraus.

N.s Text entspricht mit wenigen Ausnahmen (101 Anm. 304) dem von Sykutris. ${ }^{2}$ Er ist aber leider voll von Tipp- und Formatierungsfehlern, wie das gesamte Buch (angefangen vom Titel auf dem Buchrücken). ${ }^{3}$

\footnotetext{
${ }^{2}$ D.h. dem Text in der Anm. 1 zitierten Ausgabe.

${ }^{3}$ Viele Corrigenda hat der Autor auf seiner Homepage zusammengestellt: http://members.optusnet.com.au/t.natoli/.
} 
Dem Kommentar (110-160) folgen drei Appendices. In der wichtigen Appendix 1 (161-174) versucht N., den anonym überlieferten 31. Sokratikerbrief als einen genuinen Brief Platons an Philippos zu erweisen. Der Brief bezeugt Platons Sorge um Philippos während der Regierungszeit seines Bruders. N.s Ansicht, er sei als ,Anlage' mit Speusippos' Brief an Philippos versandt worden, ist wohl zu modern gedacht. Die Argumente für die Echtheit sind wenig überzeugend, da die von N. aus dem 4., 5. und 13. platonischen Brief gewonnenen Argumente aus Texten stammen, deren Authentizität ebenfalls zweifelhaft ist und zu erweisen wäre.

N.s Studie stellt einen wichtigen Beitrag zum Verständnis des politischen Engagements athenischer Intellektueller im 4. Jh. dar. Er hat nach B.-S. nochmals deutlich gemacht, daß der Brief dem 4. Jh. entstammt und daß viel für Speusippos als Autor spricht. Er könnte aber m.E. auch aus dem Scholarchat des Xenokrates stammen, geschrieben von einer Person, welche die Zeit um 342 schon bewußt erlebt hat. In den Jahrzehnten nach Platons Tod entstanden wohl einige der platonischen Briefe, die in den Tetralogien enthalten sind, und so mag man auch im Nachhinein ein Schriftstück konstruiert haben, das wie der 5. Brief des Corpus Platonicum das Verhältnis der Akademie zu Philippos beleuchtet. Es wäre eine umfassende Studie zu Echtheit und Datierung der platonischen Briefe wünschenswert, aus der sich vielleicht auch für den 30. Sokratikerbrief neue Gesichtspunkte hinsichtlich der Echtheit und Entstehungszeit ergeben.

Stefan Schorn

Würzburg 